\title{
Molecular detection of Mycobacterium tuberculosis and its relationship to histopathological diagnosis in paraffin-embedded lymph node tissues
}

\author{
Ihab Hamed Nourein ${ }^{1}$, Hussain Gadelkarim Ahmed ${ }^{2}$, Hassan Elsiddig Hassan ${ }^{1}$, \\ Maysa Badawi EImubasher ${ }^{3}$, Sara Abul Gasim Seif el din $^{4}$, Moawia Ahmed Elbadri ${ }^{5}$, \\ Omer Mohammed Shoaib ${ }^{6}$, Saadalnour Abusail Mustafa ${ }^{7}$
}

\footnotetext{
${ }^{1}$ Department of Histopathology and Cytology, Sudan University Of Sciences and Technology, Sudan

${ }^{2}$ Department of Pathology, College of Medicine, University of Hail, KSA

${ }^{3}$ Department of Histopathology \& Cytology, Faculty of Medical Laboratory Science, University of Science \& Technology, Sudan

${ }^{4}$ Department of Histopathology \& Cytology, Faculty of applied sciences, University Qasim, KSA

${ }^{5}$ Department of Microbiology, Faculty of Medicine, Najran University, KSA

${ }^{6}$ Department of Clinical Chemistry, Faculty of Medical Laboratory Sciences, Alzaeim Alazhari University, Sudan

${ }^{7}$ Department of Histopathology and Cytology, Faculty of Medical Laboratories Sciences, Al-Neelain University, Sudan
}

Received: 21 October 2015

Accepted: 20 November 2015

\section{* Correspondence:}

Dr. Ihab Hamed Nourein,

E-mail: ihab213@gmail.com

Copyright: (C) the author(s), publisher and licensee Medip Academy. This is an open-access article distributed under the terms of the Creative Commons Attribution Non-Commercial License, which permits unrestricted non-commercial use, distribution, and reproduction in any medium, provided the original work is properly cited.

\section{ABSTRACT}

Background: Tuberculous lymphadenitis (TBL) is one of the most common forms of extra pulmonary tuberculosis (EPTB) worldwide, with difficulty in its diagnosis. And since in the Sudan, the routinely used method for diagnosis is conventional histopathology, the aim of this study was to confirm the histopathological diagnosis by polymerase chain reaction (PCR).

Methods: In this study 718 lymph node (LN) biopsies were retrieved, of which 161 were diagnosed as TBL (histopathological evidences). PCR technique was performed for all 161 positive samples to detect the IS6110 sequence of $M$. tuberculosis as well as to obtain the sensitivity and specificity of morphological diagnosis.

Results: Out of 161 specimens 135 (84\%) were found to be positive with PCR, the remaining 26 (16\%) were negative.

Conclusions: Although PCR indicated high sensitivity it can't be a substitute for conventional histopathology in the diagnosis of tuberculous lymphadenitis in tissue.

Keywords: Tuberculosis, Tuberculous lymphadenitis, TBL, Sudan

\section{INTRODUCTION}

Tuberculosis TB Primarily considered a pulmonary disease, tuberculosis can affect almost any organ system, with lymph node involvement being the most common form of extrapulmonary tuberculosis. ${ }^{1}$
HIV infection and other immune-compromising conditions have resulted in an increase in the incidence of tuberculous lymphadenitis. ${ }^{2}$ In developing countries where the incidence of $\mathrm{Tb}$ is high, tuberculous lymphadenitis is one most frequent causes of lymphadenopathy. ${ }^{3}$ 
Tuberculosis (TB) is a major health problem world wise, it responsible of 8.8 million and 1.4 million mortality and morbidity. In Africa, Asia, America and Europe TB Kills 50, 27, 2.1, and 7 per 100.000 person respectively. ${ }^{4}$ In Sudan, tuberculosis is considered as one of the most common causes of death. The absolute number of cases in Sudan is not known, but the WHO estimated incidence average rate of TB disease in 2008, 2009 and 2010 were 119 per 100000 population. ${ }^{5,6}$

The main risk factors for tuberculosis include older age, lower socioeconomic status (via crowding, homelessness, poor nutrition, etc.) and HIV. ${ }^{7}$ Other risk factors for the development of tuberculosis include smoking, alcohol consumption, shortage of food, and contact with TB patients. ${ }^{8}$ Diagnosis of TB relies on radiology (commonly chest X-rays), tuberculin skin test, blood tests, as well as microscopic examination and microbiological culture of bodily fluids. ${ }^{9}$ Diagnosis of tuberculous lymphadenitis is a challenge. The clinical criteria used for diagnosis have poor sensitivity and specificity and may lead to overdiagnosis, especially in countries with high endemic rates of tuberculosis. ${ }^{10}$

For EPTB, the most suitable choice is the use of biopsy, which will be subjected for conventional TB laboratory tests, histopathology and molecular testing. However, those expected to be affected by EPTB are only diagnosed in conventional $\mathrm{H} \& \mathrm{E}$ depending on histopathological evidences which may be subjective in many conditions. Although, there are many cases of lymphadenitis with relatively similar features, the confirmation of tuberculous lymphadenitis is only affirmed by (Zaheel- nelson Z.N stain in histological sections which has sensitivity less than $(6 \%) .^{11}$

Molecular technique such polymerase chain reaction (PCR) can be used for rapid identification of specific gene from any specimens type, even it used in fixed sample, this characteristic make them diagnostic tool is detection of $\mathrm{TB} .^{12}$

\section{METHODS}

In this study we retrieved 718 formalin fixed paraffin wax processed LN tissues with their corresponding data. Specimens included a full coverage of LN biopsies sent to histopathology laboratories in Sudan at Khartoum state during period from May 2012 to May 2014. All Information's including demographic characteristic like age, gender, and site of lymph node biopsy regarding each patient was obtained from each patient's file, and it were shown Figure 1. Screening for histopathological evidence of tuberculosis was re-performed for all specimens.

The specimens were previously processed as follows: tissue were fixed in $10 \%$ formalin and then processed by tissue processing machine adopting 24-hours scheduling. Parallel, 5-micron thick sections were prepared from each patient's block using rotary microtome, and it was stained with hematoxylin and eosin.

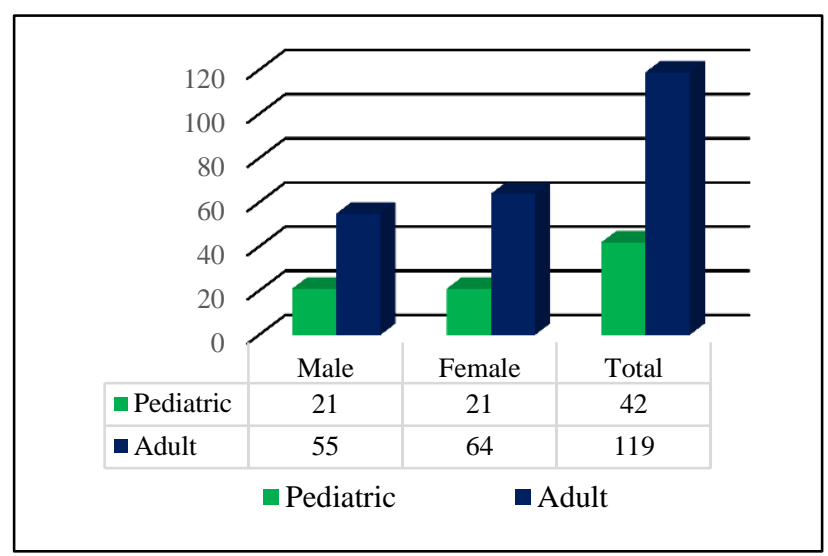

Figure 1: Description of the study population.

10 micron tissue sections were obtained and placed in Eppendorf" tube. Carry-over tissue contamination was prevented by cleaning the blade with $96 \%$ ethanol after sectioning each sample; the DNA extraction was done for samples by kit for rapid extraction of formalin fixed paraffin embedded tissues, of (Adilab biotechnologies co) Manufacturer Company for in vitro use.

All the tubes containing extracted DNA required for the amplification subsequently it was subjected to PCR technique for detection of the IS6110 sequence of M tuberculosis as described in Table 1.

\section{Data analysis}

Data entry and analysis was done using SPSS 20 for windows. Pearson's chi-square test was used to determine the significance among categorical variables. Nonparametric tests were used for two-group comparisons. Differences were considered statistically significant if $\mathrm{p}$ $\leq 0.05$.

Table 1: PCR program used for amplification of IS16110 oligonucleotide.

\begin{tabular}{|c|c|c|c|}
\hline \multicolumn{4}{|c|}{$\begin{array}{l}\text { Thermocyclers with block temperature adjustment } \\
\text { "'miniCycler" "'PTC-100' (MJ research) }\end{array}$} \\
\hline Step & Temperature $\mathrm{C}^{\mathrm{O}}$ & Time & Cycles \\
\hline 1 & $95 \mathrm{C}^{\mathrm{O}}$ & Pause & \\
\hline 2 & $95 \mathrm{C}^{\mathrm{O}}$ & $15 \mathrm{~min}$ & 1 \\
\hline \multirow{2}{*}{3} & $95 \mathrm{C}^{\mathrm{O}}$ & $30 \mathrm{sec}$ & \multirow{2}{*}{42} \\
\hline & $70 \mathrm{C}^{\mathrm{O}}$ & $40 \mathrm{sec}$ & \\
\hline 4 & $72 \mathrm{C}^{\mathrm{O}}$ & $2 \mathrm{~min}$ & 1 \\
\hline 5 & $10 \mathrm{C}^{\mathrm{O}}$ & Storage & \\
\hline
\end{tabular}

\section{RESULTS}

After re-assessment 718 of lymph node specimens by histopathology (depending on histopathological evidence 
of TB), tuberculosis was diagnosed in 161 specimens. The age of these patients with tuberculosis ranged between 4 and 80 years with a mean age of 29 years old. Of 161 patients, 42/161 (26) were children and the remaining 119/161 (74\%) were adults. The highest frequency of study subjects were identified in age group (19-30) which represented 63 (39\%) of study population, followed by age groups (8-18) and (31-40) which represented $29(18 \%)$ and $25(16 \%)$ respectively. Age group 51+, >8 years and (40-50) represent 20 (12\%), 13 (8\%) and $11(7 \%)$ correspondingly, as showed in Table 2. The distribution of the study population by lymph node site regarding each patient's described in Figure 2. The great majority of the specimens were obtained from cervical lymph node followed by axillary lymph node representing $100(62 \%)$ and $17(11 \%)$ respectively. The other sites include mediastinal, mesenteric, inguinal, and submandibular, constituting $10(6 \%), 7(4 \%), 7(4 \%)$, and $4(3 \%)$ correspondingly, the remaining was unknown representing $16(10 \%)$. Both necrotic and non-necrotic granulomas with epithelioid cells and multinucleated giant cells characteristic of tuberculosis were observed in these patients. Those showing histopathological pattern containing (giant cells + granuloma + caseation) were considered as strong evidence, and the other showing less evidences (e.g., ill-defined aggregates of epithelioid histiocytes only, granulomas without necrosis and giants cells, etc.) were considered as weaker evidence. Accordingly, the strong evidence (positive) was used as a gold standard for comparing the other variables. Accordingly, of the 161 patients, 118 were categorized as having strong evidences (positive) and the remaining 43 were detected with weaker evidences (positive), cases as indicated in Table 3 .

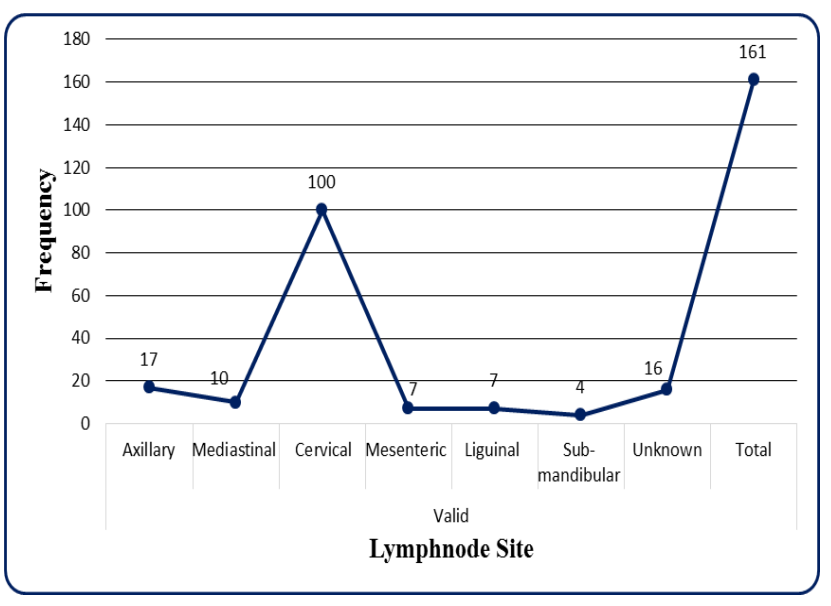

Figure 2: Showing description of the study population by lymph node site.

Of 161 studied lymph nodes, 135 (84\%) were found positive with PCR technique 33 were pediatric, 102 Adult, 68 male and 67 female respectively. Out of the entire 135 PCR positive, 106 cases were previously found as strong evidence positive and 29 was found weak evidence. Of remaining $26(16 \%)$ PCR negative specimens only 12 specimens were showed strong evidence for TB, and 14 were weak evidence.

Table 2: Distribution of the study population by age.

\begin{tabular}{|lllll|}
\hline $\begin{array}{l}\text { Age in } \\
\text { year }\end{array}$ & Frequency & Percent & $\begin{array}{l}\text { Valid } \\
\text { percent }\end{array}$ & $\begin{array}{l}\text { Cumulative } \\
\text { percent }\end{array}$ \\
\hline$>8$ & 13 & 8.1 & 8.1 & 8.1 \\
\hline $8-18$ & 29 & 18.0 & 18.0 & 26.1 \\
\hline $19-30$ & 63 & 39.1 & 39.1 & 65.2 \\
\hline $31-40$ & 25 & 15.5 & 15.5 & 80.7 \\
\hline $41-50$ & 11 & 6.8 & 6.8 & 87.6 \\
\hline $51+$ & 20 & 12.4 & 12.4 & 100.0 \\
\hline Total & 161 & 100.0 & 100.0 & \\
\hline
\end{tabular}

Table 3: Distribution of the study subjects by lymph node site and TB strong or weak evidences.

\begin{tabular}{|llll|}
\hline \multirow{2}{*}{ Lymph node Site } & Strong & Weaker & Total \\
\hline Cervical & 75 & 25 & 100 \\
\hline Mediastinal & 7 & 3 & 10 \\
\hline Axillary & 12 & 5 & 17 \\
\hline Mesenteric & 5 & 2 & 7 \\
\hline Inguinal & 5 & 2 & 7 \\
\hline Sub- mandibular & 3 & 1 & 4 \\
\hline Unknown & 11 & 5 & 16 \\
\hline Total & $\mathbf{1 1 8}$ & $\mathbf{4 3}$ & $\mathbf{1 6 1}$ \\
\hline
\end{tabular}

\section{DISCUSSION}

In this retrospective descriptive study, the total of study subjects $(n=161)$ were previously diagnosed as having lymph node TB, depending on the presences of variable histological TB evidences. We reassessed these evidences, by grouping of the histological features, depending on the strongest histological features of TB. All histological tissues that showed the presence of caseation, granuloma, and Langhans giant cells were considered as positive "strong standard." Out of the 161 TB patients, $118(73 \%)$ were found with strong histological evidence of TB. Such findings have been previously reported, separately counting different features. ${ }^{7}$ There are two specific pathologic criteria for identifying tuberculosis lymphadenitis, caseation and granuloma formation. Caseation has been found to be more specific and sensitive. ${ }^{13}$

In our study, $118(73 \%)$ lymph nodes were of caseating granuloma type and $42(27 \%)$ were of noncaseating granuloma type. This is in correlation with Woodard et al who documented $67 \%$ caseating granuloma. ${ }^{14}$ Other workers reported $76 \%$ caseating granuloma and $24 \%$ noncaseating granuloma, Fatmi and Jamal, reported $62 \%$ caseating granulomas and $38 \%$ non caseating granuloma, also Hussain and Akram reported $32(32 \%)$ caseating and 68 (68) non caseating granulomas. ${ }^{15-18}$ However in our study caseation to some extend has been found to be 
sensitive $(78.5 \%)$ but less specific $(46.1 \%)$ with PPV (100\%) and NPV $(32.5 \%)$ comparing with PCR results which used as gold standard in this study.

In recent years, PCR methods have increasingly been developed for the most important species of mycobacteria. Some tests are already commercially available in Sudan but are not used as a complementary diagnostic tool. ${ }^{19-21}$

Our study showed that $135(84 \%)$ of all cases were positive with PCR, while remaining were found negative. The distribution of PCR positive results among study subjects as showed in Table 4 were found as follow, cervical lymph node express the highest frequency of positive result $83(62 \%)$ of all 135 positive cases, followed by axillary lymph node 14 (10\%), mediastinal, mesenteric, inguinal, and submandibular lymph node 7 $(5 \%), 5(4 \%), 5(4 \%)$ and $4(3 \%)$ respectively, the remaining was unknown site 15 (11), these findings are in agreement with Pooja and Anju, they reported that out of 100 cases of lymphadenopathy, 78 (78\%) cervical lymph node, $10(10 \%)$ axillary lymph node expressed positive results with $\mathrm{PCR}{ }^{22}$

Table 4: The correlation between lymph node site and PCR result.

\begin{tabular}{|llll|} 
& \multicolumn{2}{l|}{ IS6110 PCR } & \\
Lymph node Site & $+\mathbf{+ V e}$ & \multicolumn{1}{l|}{-Ve } & Total \\
\hline Cervical & 83 & 17 & 100 \\
\hline Mediastinal & 7 & 3 & 10 \\
\hline Axillary & 12 & 5 & 17 \\
\hline Mesenteric & 5 & 2 & 7 \\
\hline Inguinal & 5 & 2 & 7 \\
\hline Sub- mandibular & 4 & 0 & 4 \\
\hline Unknown & 15 & 1 & 16 \\
\hline Total & 118 & 43 & 161 \\
\hline
\end{tabular}

Out of ( $n=161)$ of study subjects $100(62 \%)$ specimens were cervical lymph node, the other sites include mediastinal, mesenteric, inguinal, and submandibular, representing $10(6 \%), 7(4 \%), 7(4 \%)$, and $4(3 \%)$ correspondingly, the remaining was unknown representing $16(10 \%)$. This is in correlation with studywhich documented $74(74 \%)$ cervical lymph node out of 100 lymph node specimens. ${ }^{18}$ Some studies by chen et al, have shown that, cervical nodes were affected in about $90 \%$ of cases. ${ }^{23}$

Furthermore, a study reported that the highest rate of TB infection is an at age ranged from 22-38 which in agreement with our results that showed the tuberculosis infection can affect adults and children at any time and age in which the disease appeared among the patients at ages starting from 4 to 80 years, but the statistically the results showed that the higher frequency of study population were showed in age group (19-30) which represent $63(39 \%)$ of study population, followed by age group (8-18) and (31-40) which represent 29 (18\%), respectively, those patients are the most harbor the disease. Therefore, our results are in support to the findings of Nomani et al they reported that the maximum incidence was found to be in the age group 10-30 years. $^{18,24}$

In this study, the rate of infection among females was $53 \%$ which is slightly higher than infection among males which was $47 \%$. These results to some extend were in agreement with another study (17), which reported that out of (100) lymph node tuberculosis 66 patients $(66 \%)$ were females and $34(34 \%)$ were males, and the study which reported $70(70 \%)$ females and $30(30 \%)$ males. $^{18}$

\section{CONCLUSION}

In conclusion tuberculous lymphadenitis is prevalent among Sudanese patients with lymphadenopathy. Further, deeper studies are required for more precise measures of the relationship between PCR reports and presence of histopathological evidence for diagnosis of tuberculous lymphadenitis.

Funding: No funding sources

Conflict of interest: None declared

Ethical approval: The study was approved by the Institutional Ethics Committee

\section{REFERENCES}

1. Van den Broek J, Mfinanga S, Moshiro C, O'Brien $\mathrm{R}$, Mugomela A, Lefi M. Impact of human immunodeficiency virus infection on the outcome of treatment and survival of tuberculosis patients in Mwanza, Tanzania. Int $\mathbf{J}$ Tuberc Lung Dis. 1998;2:547-52.

2. Small PM, Schecter GF, Goodman PC, Sande MA, Chaisson RE, Hopewell PC.. Treatment of tuberculosis in patients with advanced human immunodeficiency virus infection. $\mathrm{N}$ Engl J Med. 1991;324:289-94.

3. Gupta AK, Nayar M, Chandra M. Critical appraisal of fine needle aspiration cytology in tuberculous lymphadenitis. Acta Cytologica. 1992;36(3):391-4.

4. World Health organization (WHO).Tuberculosis. Available at:http://www.who.int/ mediacentre/ factsheets/fs104/en/index.html, 2010.

5. Public Health Agency of Canada. International Tuberculosis Incidence Rates. Available at: http://www.phac-aspc.gc.ca/tbpc-latb/itir-eng.php, 2012.

6. National tuberculosis control program (NTCP). Ministry of Health Sana'a Yemen. Annual Health Report 2003.

7. Vincent BY, William AK, Allan HG. Blueprints Medicine, Blackwell. 3rd edition, 2003.

8. Tekke M, Rahu M, Loit H M, Baburin A. Risk factors for pulmonary tuberculosis in Estonia. 
International Journal of Tuberculosis and Lung Disease. 2002;6(10):887-94.

9. Jasmer RM, Nahid P, Hopewell PC. Clinical practice, Latent tuberculosis infection. N Engl J. Med. 2002;347(23):1860-6.

10. Mfinanga SG, Morkve O, Sviland L. Patient knowledge, practices and challenges to health care system in early diagnosis of mycobacterial adenitis. East Afr Med J. 2005;82:173-80.

11. Grange JM. The rapid diagnosis of paucibacillary tuberculosis. Tubercle. 1989;70(1):1-4.

12. Amand ALS, Frank D N, De Groote M A, Basaraba RJ, Orme IM, Pace NR. Use of specific rRNA oligonucleotide probes for microscopic detection of Mycobacterium tuberculosis in culture and tissue specimens. J Clin Microbiol. 2005;43:5369-71.

13. Finfer MA, Burstein DE. Fine needle aspiration biopsy diagnosis of tuberculous lymphadenitis in patients with and without the acquired immune deficiency syndrome. Acta Cytologica. 1991;35(3): 325-32.

14. Woodard BH, Rosenberg S, Farnham R, Adams DO. Incidence and nature of primary granulomatous inflammation in surgically removed material. American Journal of Surgical Pathology. 1992;6(2):119-29.

15. Kumar N, Tiwari MC, Verma K. AFB staining in cytodiagnosis of tuberculosis without classical features: a comparison of Ziehl-Neelsen and fluorescent methods. Cytopathology. 1998;9(3):20814.

16. Lake AM, Oski FA. Peripheral lymphadenopathy in childhood. Ten-year experience with excisional biopsy. American Journal of Diseases of Children. 1978;132(4):357-9.

17. Fatmi TI, Jamal Q. A morphological study of chronic granulomatous lymphadenitis with the help of special stains. Pakistan Journal of Medical Sciences. 2002;18(1):48-51.
18. Hussain GA, Akram S, Ibrahim G. Screening for Tuberculosis and Its Histological Pattern in Patients with Enlarged Lymph Node. SAGE-Hindawi Access to Research Pathology Research International. 2011;2011:Article ID 417635.

19. Chakaravorty S, Sen MK. Diagnosis of extra pulmonary tuberculosis by smear, culture, and PCR using universal sample processing technology. J Clin Microbiol. 2005;43:4357-62.

20. Therese KL, Jayanthi U, Madhavan HN. Application of nested polymerase chain reaction (nPCR) using MPB 64 gene primers to detect Mycobacterium tuberculosis DNA in clinical specimens from extrapulmonary tuberculosis patients. Indian J Med Res. 2005;122:165-70.

21. Park DY, Kim JY, Choi KU, Lee JS, Lee CH, Sol MY, et al. Comparison of polymerase chain reaction with histopathological features for diagnosis of tuberculosis in formalin-fixed, paraffin-embedded histologic specimens. Arch Pathol Lab Med. 2003;127:326-30.

22. Verma P, Jain1 A, Kumar S. Evaluation of Polymerase Chain Reaction (PCR) using hupB gene in diagnosis of tuberculosis in fine needle aspiration. Indian J Tuberc. 2010;57:128-33.

23. Chen YM, Lee PY, Su WJ, Perng RP. Lymph node tuberculosis: 7-year experience in veterans general hospital, Taipei, Taiwan. Tubercle and Lung Disease. 1992;73(6):368-71.

24. Nomani K, Kazi B M, Ahmad K, Karamat KA.. Frequency of tuberculous cervical lymphadenitis detection at a single laboratory in Islamabad. Journal of the College of Physicians and Surgeons-Pakistan. 2007;7(7):410-2.

Cite this article as: Nourein $\mathrm{IH}$, Ahmed HG, Hassan HE, Elmubasher MB, Seif el din SAG, Elbadri MA, Shoaib OM, et al. Molecular detection of Mycobacterium tuberculosis and its relationship to histopathological diagnosis in paraffin-embedded lymph node tissues. Int J Res Med Sci 2016;4:13971401. 